\title{
Commonplace
}

\section{The Internet isn't just a \\ technology, it's an \\ ecosystem}

\section{Michelle Ciccone}

Published on: Aug 10, 2020

DOI: $10.21428 / 6 \mathrm{ffd} 8432.346 \mathrm{f009b}$

License: Creative Commons Attribution 4.0 International License (CC-BY 4.0). 
Much of primary school curriculum centers attention on your place within your local context. In social studies, you explore the responsibilities of community membership and study your state and town history. You might have even gone on a field trip to your city or town hall to witness the inner workings of local government. In science, you observe the natural world around you and measure the impact that certain things-plants, animals, you-have on your environment.

Growing up on the Massachusetts coast, for me that meant that the culminating science unit of seventh grade was focused on our coastal ecosystem. We learned about the rhythm of the tides and the pull of the moon, the birds and sea creatures unique to our corner of the seashore, the role that beach grass plays in maintaining the stability of the sand dunes - all leading to a nearly two mile walk to the public beach, where, among other things, we collected shells for a plaster of Paris still life that's still on display in my parent's house.

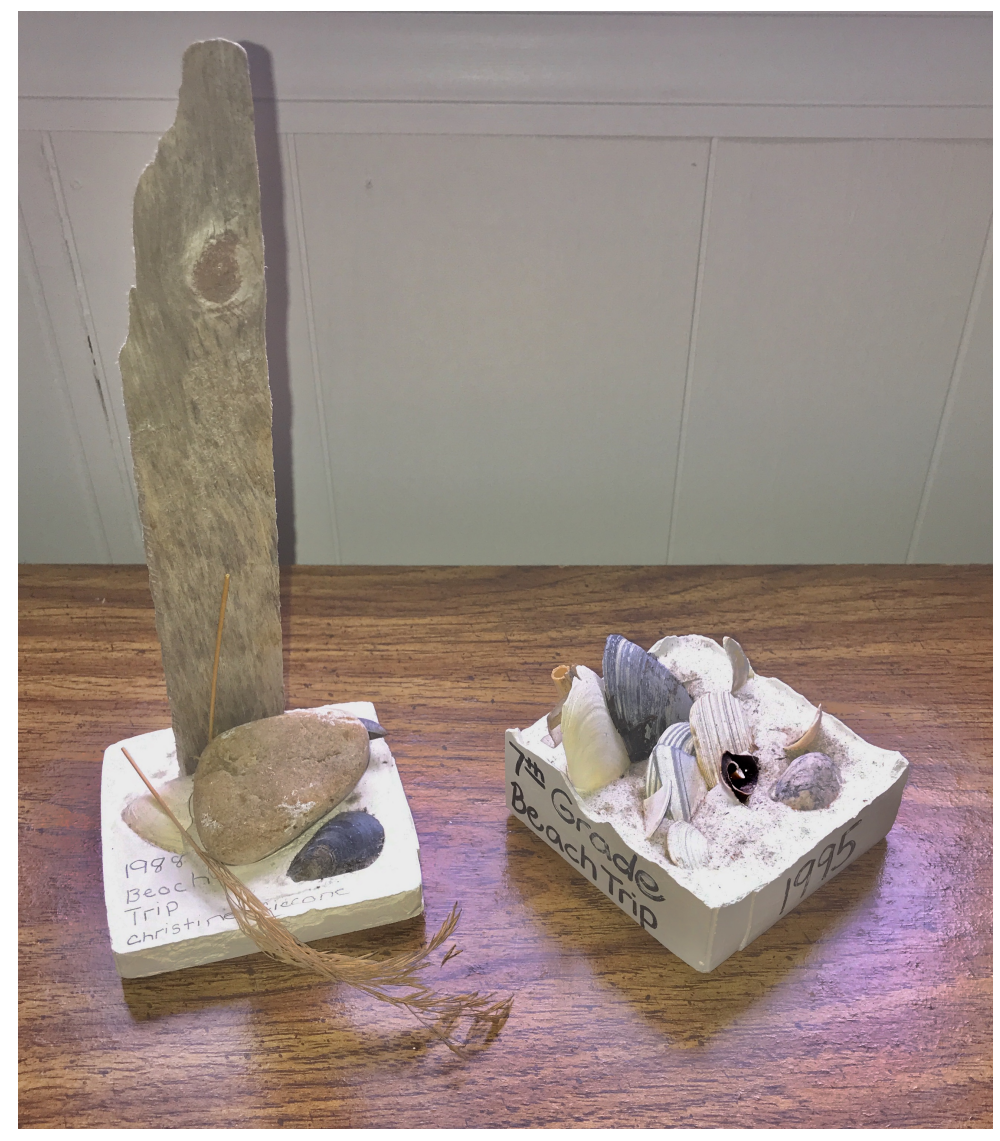


We know how important it is for children to be able to conceptualize the invisible forces that order the world around them, from the work that goes on in city hall to the tidal system that causes the sea to rise and fall. Articulating this invisible architecture helps us to identify the true impact our actions can have on our environment, including impacts that aren't immediately obvious or ever even visible to our eye. What I learned about the ocean impacted how I treated my surroundings. When I spent the afternoon at the beach with my Dad I knew to not run on the dunes, no matter how fun sliding down those rolling sandy hills could be, because I had learned that the dunes help protect the beach from erosion. Once I understood, on a structural level, how the coastal ecosystem worked, I came to understand how I could contribute to its continued health.

When I became a middle school teacher, I carried this ethos into my own classroom. But, as a digital and media literacy teacher, the environment that I was tasked with helping my students understand and learn to tend to was the Internet. I knew that I needed to help my students gain a structural understanding of the Internet, so that online they could act intentionally, capably, and with care, and to know what proverbial dunes not to run down.

Almost by design, the Internet is a difficult environment to conceptualize. It is "the cloud," after all; its bits and pieces have been made invisible. Its wireless waves are hidden in the air like electrical wiring is hidden in our walls. In some ways getting online is as simple as flipping the switch that turns on your overhead light. But use of the Internet-actually navigating this environment-requires certain skills and dispositions, knowledge and intuition. And even then we can find ourselves in corners we never intended to go. This simultaneous sense online that we know plenty and yet will never know enough can be disorienting.

Young people are not immune to this feeling either. Luci Pangrazio's research on teenagers' digital literacies uncovered that her teenage participants had internalized two clashing messages: that the Internet is an unsafe place, but that they are the "digital natives" and therefore best equipped to navigate the digital realm. And so, this messaging goes, the Internet is dangerous and you're on your own to figure it out.

I invariably observed this same disorientation in my own 8th graders. There was a sense from many that the Internet is a dark and unknowable place, a clearly alienating and dispiriting proposition. And because I taught this class from 2015-2019, a period when the impact of online life on our politics was becoming obvious to even the more disengaged, I felt a distinct need to help my students see more clearly online. I knew we had to dig deeper than the messages they were used to receiving, which tend to focus on cyberbullying, stranger danger, and the near constant warning that "you just can't trust anything you find online." (It's no wonder, then, that the Internet feels like such a dangerous place to them, if all they ever hear about are dangers.) So together we set out to get a lay of the land, to focus 
our attention on how the Internet works, to identify its components and the invisible structural forces hidden in the cloud.

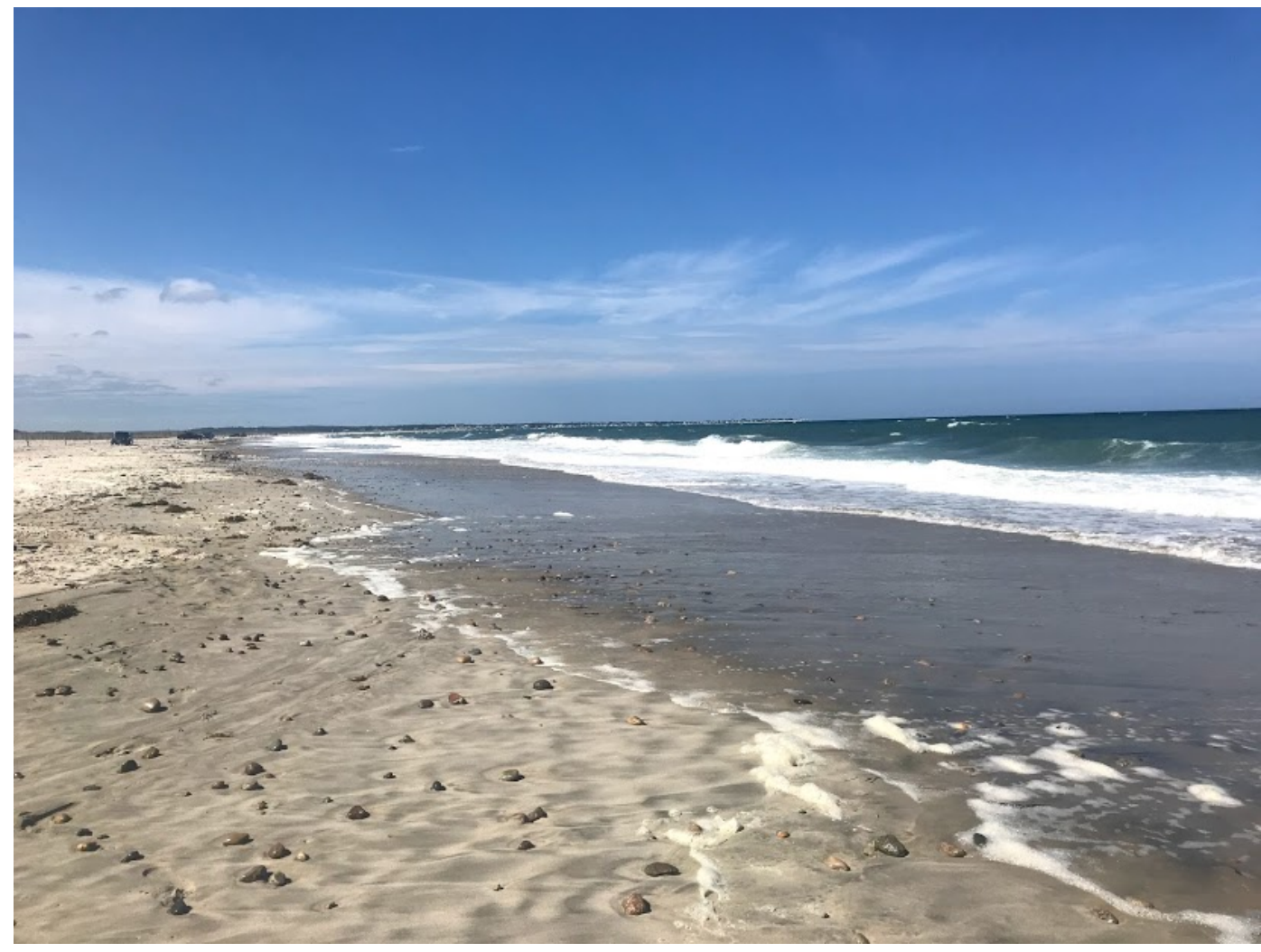

The Massachusetts coast
We started with the physical. We traced the

undersea cables that connect continents to the Internet along historical trading routes. We looked to infographics to understand that Internet access varies in both cost and speed around the world and even within the United States itself. We learned that this variability is not random at all, but attributable to a lack of competition amongst a limited number of Internet Service Providers in the US. We studied the difference between the older copper wires that still connect many of our homes to the Internet versus the faster but more expensive fiber optic cables that ISPs are slow to upgrade their infrastructure to. We looked at Europe's General Data Protection Regulation (GDPR) and so called "right to be forgotten law" to see that there is more than one possible regulatory orientation towards user digital data rights and protections. We considered the ubiquitous "cookie" and how this bit of code we agree to embed within our browsers enables a personalized web experience. And, though convenient, in not too many steps this widely enabled personalization gets us to filter bubbles and variable pricing, revealing, as ProPublica notes, that "mass customization can mean mass discrimination." We gathered what information we could about how the Google Search algorithm works and learned that though algorithms are popularly positioned as neutral and precise, they in 
practice amplify and reflect the bigoted ideologies and power imbalances codified by the broader societal landscape.

By examining the Internet itself - as an environment that we could observe and study-we learned that it is not naturally occurring or predetermined, but rather that it has been built by other humans, constructed and pieced together, enacting a historically-situated ideological architecture that is no less real if it is made hidden by a cloud. Considered concretely, the Internet becomes both more fantastical and more banal, an amazing and most ordinary thing. Real but still malleable.

Once we made the Internet a more legible ecosystem, my students came to understand where they might take care and pay attention, apply force, see impacts, stretch boundaries, and redefine relationships. Students started sending me screenshots of particularly egregious passages in Terms of Service documents they were forced to agree to. They emailed me their commentary on the net neutrality regulatory battle. After watching Keiichi Matsuda's provocative Hyper-Reality, they passionately called for a digital future that prioritized human autonomy over isolating personalization. Just as I had learned how to care for my community's seashore, my students learned how to demonstrate care for the collective digital environment. It was honestly thrilling.

Actually seeing the Internet does not guarantee careful and ethical participation online. But if we don't see the environment for what it is we can never meaningfully contribute to its continued evolution as a thriving and healthy ecosystem - and we are much more likely to engage in behavior that harms the environment. As Ingrid Forsler notes, "When media infrastructures become such an embedded part of our lived environments that they fade into the background, they also become harder to critique." Truly perceiving these infrastructures, Forsler argues, can help invite young people to "renegotiate future imaginaries and formulate questions around what kind of society we want to live in." The work of future-building is never done, and we certainly need all the help we can get. 